\title{
IN-VITRO SUSCEPTIBILITY OF MYCOBACTERIUM FOR- TUITUM AND RELATED STRAINS TO CEPHALOSPORINS
}

\author{
Hava HaAs, J. Michel and T. G. Sacks \\ Department of Clinical Microbiology, Hadassah University Hospital, and Hebrew \\ University-Hadassah Medical School, Jerusalem, Israel
}

MYCOBACTERIUM FORTUITUM, a rapidly growing mycobacterium belonging to Runyon's group IV, is often considered to be a saprophytic organism. It has, however, been well documented as a cause of human disease, and more than 20 reports of cutaneous lesions, abscesses, pulmonary and corneal infections are quoted in a recent review (Hand and Sanford, 1970). Biochemical and antigenic studies (Stanford and Beck, 1969; Nakayama, Nakayama and Takeya, 1970; Tsukamura, 1970) have established the existence of the closely related species $M$. abscessus ( $M$. runyonii or $M$. friedmannii) and $M$. borstelense, which can produce disease in man identical to that produced by $M$. fortuitum (Hand and Sanford). All three species are resistant to the usual antimycobacterial agents. Isolated reports have appeared of their sensitivity to antibiotics such as tetracyclines (Brosbe et al., 1964), erythromycin (Molavi and Weinstein, 1971a) and rifampin (Molavi and Weinstein, 1971b) but little is known of the effect of the numerous other antibacterial drugs on these three species. This paper reports on the susceptibility of $M$. fortuitum, M. abscessus and $M$. borstelense to cephaloridine and cephalothin.

\section{MATERIALS AND METHODS}

The 36 strains of rapidly growing mycobacteria studied were as follows: $M$. fortuitum (ATCC no. 9820); $M$. fortuitum (TMC [Trudeau Institute] no. 1529); $M$. abscessus (TMC no. 5129); $M$. borstelense (TMC no. 1524); six strains of $M$. borstelense and 12 of $M$. abscessus received from Dr J. L. Stanford, London; five strains of $M$. borstelense received from Dr Freerksen, Borstel, Germany. Seven strains identified as $M$. fortuitum and one as $M$. abscessus were isolated from clinical material in our laboratory or received from other laboratories. The strains isolated from clinical material were identified according to arylsulphatase activity, nitrate reduction, growth and acid production on McConkey agar, growth at $37^{\circ} \mathrm{C}$ and at $30^{\circ} \mathrm{C}$.

The sensitivity tests were performed on Dubos Oleic Agar Base (Difco) enriched with Dubos Medium Albumin (Difco). Freshly prepared two-fold dilutions of penicillin G, methicillin, ampicillin, carbenicillin, cephaloridine, and cephalothin were added to the molten medium, which was then poured into petri dishes. Subcultures of each strain were made in Dubos Broth Medium (Difco) enriched with Dubos Medium Albumin (Difco). After incubation for $3-5$ days at $37^{\circ} \mathrm{C}$, each culture was diluted in sterile distilled water to a turbidity approximating that of the McFarland 1 standard ( $1 \mathrm{mg}$ of bacterial mass per $\mathrm{ml}$ ), and $0.15 \mathrm{ml}$ of a 1 in 1000 dilution of this suspension was spread with a glass rod over the surface of the antibiotic-containing plates. Antibiotic-free plates were inoculated with $0.15 \mathrm{ml}$ of 1 in 100,1 in 1000 and 1 in 10,000 dilutions of the McFarland 1 standard 
suspension to serve as controls of the density of the inoculum. The plates were incubated at $37^{\circ} \mathrm{C}$ in sealed metal containers. Results were read at 3 and 6 days. The lowest concentration of the antibiotic completely inhibiting at least 99 per cent. of the growth was considered to be the minimum inhibitory concentration (MIC). With each strain, the sensitivity tests for each antibiotic were repeated three to five times.
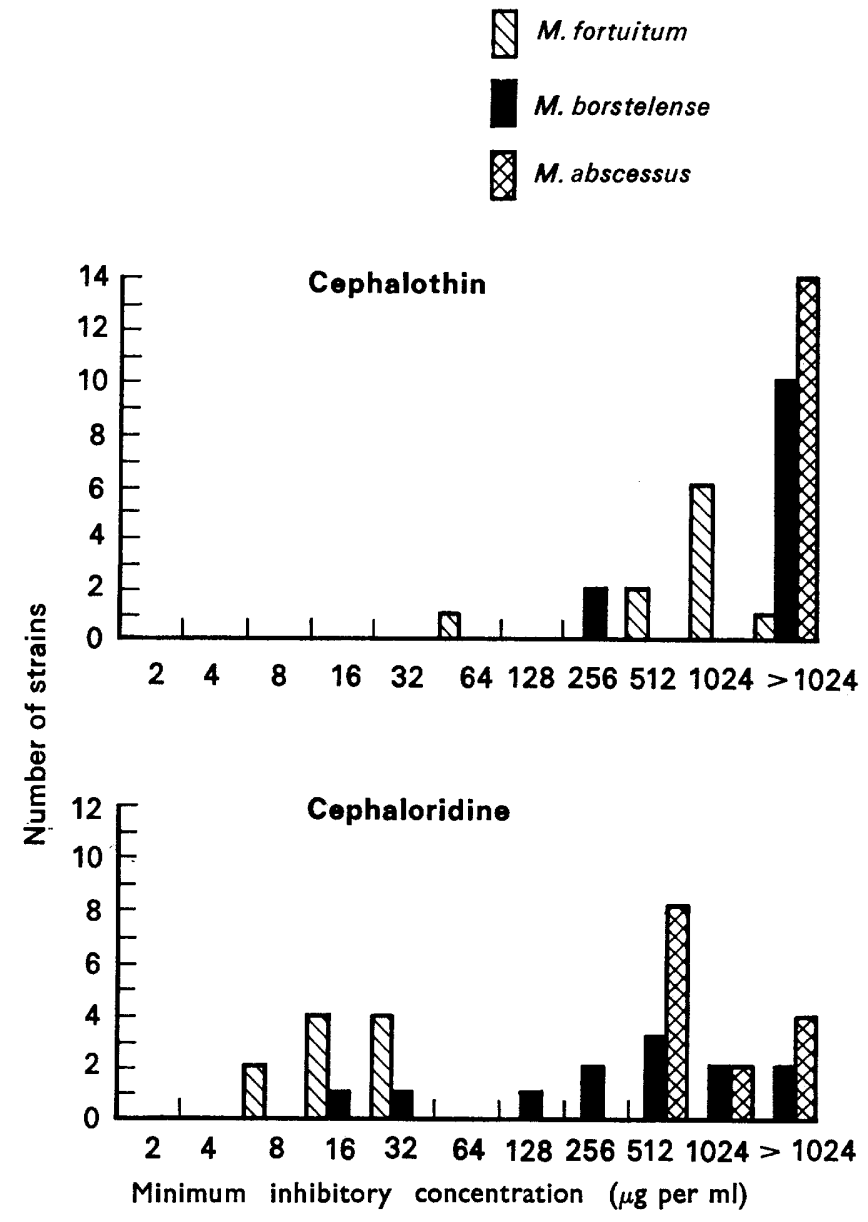

FIGURE.-Minimum inhibitory concentrations of cephaloridine and cephalothin for Mycobacterium fortuitum, M. abscessus and $M$. borstelense.

Disk-sensitivity tests with $30 \mu \mathrm{g}$-cephaloridine and -cephalothin disks (BBL Laboratories, Maryland, USA) were performed on Dubos Oleic Agar Base (Difco) enriched with Dubos Medium Albumin (Difco). The inoculum was $0.15 \mathrm{ml}$ of a 1 in 1000 dilution of the McFarland no. 1 suspension. Results were read at 3 and 6 days and the diameter of the zones of inhibition was measured.

\section{RESULTS}

The sensitivity patterns, which were constant and reproducible on repetition, are shown in the figure. The ten strains of $M$. fortuitum were all sensitive to cephaloridine but, with one exception, all highly resistant to cephalothin 
(mean MIC: cephaloridine $20 \mu \mathrm{g}$ per $\mathrm{ml}$; cephalothin $800 \mu \mathrm{g}$ per $\mathrm{ml}$ ). The MIC of cephalothin for the exceptional strain was $64 \mu \mathrm{g}$ per ml. The strains of $M$. abscessus and $M$. borstelense were resistant to cephalothin. All of the $M$. abscessus strains, and all but two strains of $M$. borstelense were also resistant to cephaloridine. The two exceptions-Stanford's strains no. 78 (NCTC946) and no. 482-were also slightly more sensitive to cephalothin than were the other strains of $M$. borstelense.

The strains of $M$. fortuitum were all highly resistant to penicillin $\mathrm{G}$ (mean MIC $100 \mu \mathrm{g}$ per ml), methicillin (mean MIC $512 \mu \mathrm{g}$ per ml) and carbenicillin (mean MIC $1024 \mu \mathrm{g}$ per ml) but more sensitive to ampicillin (mean MIC $30 \mu \mathrm{g}$ per $\mathrm{ml})$.

With the cephaloridine disk-sensitivity test, strains of $M$. fortuitum always showed a clear zone of inhibition at least $20 \mathrm{~mm}$ in diameter. There was no inhibition of the strains of $M$. abscessus or of $M$. borstelense, except for the two more sensitive strains of the latter species. The cephalothin disks failed to produce inhibition of any of the strains.

\section{Discussion}

There is little information available on the activity of the $\beta$-lactam group of antibiotics on mycobacteria. Hawkins and McClean (1966) showed that the growth of strain H37RV was inhibited by 50 units penicillin per $\mathrm{ml}$ in a synthetic medium, or by 200 units per $\mathrm{ml}$ in Dubos Broth Base enriched with oleic acid-albumin-dextrose complex. Against $M$. kansasii and $M$. fortuitum the drug was ineffective even at a concentration of 200 units per ml. Vaichulis and Vicher (1962) also found $M$. fortuitum to be resistant to 200 units of penicillin per $\mathrm{ml}$ of Dubos Tween Albumin Broth.

We found that, in Dubos Agar supplemented with albumin, the strains of $M$. fortuitum were highly resistant to all the penicillins examined, but slightly less resistant to penicillin $\mathrm{G}$ and ampicillin than to methicillin or carbenicillin. The difference between the MIC of the two cephalosporins for the strains of $M$. fortuitum is more important. Cephaloridine is in general more active than cephalothin against cephalosporin-sensitive strains of bacteria, but the differences are nowhere nearly as great as those seen in this study with $M$. fortuitum.

Cephaloridine may penetrate the cell more easily than does cephalothin, or $M$. fortuitum may produce an enzyme with greater activity on cephalothin than on cephaloridine. Mycobacteria are known to produce $\beta$-lactamases (Dufour, 1966), and Kasik (1968) found that the enzyme from a single strain of $M$. fortuitum hydrolysed cephalothin slightly more rapidly than cephaloridine. Preliminary studies in our laboratory showed that in the presence of actively growing $M$. fortuitum, $500 \mu \mathrm{g}$ per $\mathrm{ml}$ of cephalothin is completely inactivated in $48 \mathrm{hr}$, whereas under the same circumstances cephaloridine retains all its activity.

The greater resistance of $M$. abscessus and $M$. borstelense than of $M$. fortuitum to cephaloridine may reflect an underlying difference between these otherwise closely related strains of rapidly growing mycobacteria. This is not an isolated phenomenon, because $M$. fortuitum is sensitive to $25 \mu \mathrm{g}$ or less of 
ethambutol per $\mathrm{ml}$ whilst $M$. abscessus and M. borstelense are resistant (Portaels and Pattyn, 1970); and $M$. fortuitum is highly resistant to erythromycin whilst M. borstelense is sensitive to $0.2 \mu \mathrm{g}$ per $\mathrm{ml}$ (Molavi and Weinstein, 1971a).

One of the two cephaloridine-sensitive strains of $M$. borstelense (NCTC no. 946) was classified as $M$. fortuitum by Gordon and Smith (1955) but was reclassified as $M$. friedmannii (borstelense) by Stanford and Beck (1969). The precise taxonomy of these strains is uncertain, and it is possible that, when evidence of genetic relationships becomes available, many strains will be renamed. At the moment it seems that sensitivity to $50 \mu \mathrm{g}$ per $\mathrm{ml}$ cephaloridine (or a zone of inhibition at least $20 \mathrm{~mm}$ in diameter around a 30- $\mu \mathrm{g}$ disk) may be an additional criterion for differentiating between $M$. fortuitum and the other strains.

These results also suggest a possible therapeutic application for cephaloridine. M. fortuitum infections are notoriously difficult to treat, because they are resistant to isoniazid, PAS, streptomycin, rifampicin and ethambutol. Slight sensitivity to gentamicin and kanamycin has been reported (Nicholson and Sevier, 1971). Serum levels in excess of the MICs that we have demonstrated can be obtained by standard dosage with cephaloridine (Griffith and Black, 1971). The nephrotoxicity of this drug seems to have been exaggerated (Dillon and Postlethwait, 1971), and systemic treatment of severe infection due to $M$. fortuitum may be justified. Animal models for producing ocular mycobacterial infections have been described (Bulmer and Sexton, 1971) and we are conducting in-vivo trials to see whether the local application of cephaloridine is likely to have a place in the treatment of the more common ocular infection with $M$. fortuitum.

\section{SUMMARY}

The sensitivity of ten strains of Mycobacterium fortuitum, 14 of $M$. abscessus, and 12 of $M$. borstelense to two cephalosporins was examined. $M$. fortuitum strains were resistant to cephalothin but sensitive to cephaloridine. The $M$. abscessus and $M$. borstelense strains were all highly resistant to cephalothin. All the $M$. abscessus strains and all but two strains of $M$. borstelense were resistant to cephaloridine. The use of cephaloridine resistance as a taxonomic aid is suggested. Cephaloridine may be useful in the treatment of infections with $M$. fortuitum.

The strains used in this study were obtained from: Dr J. L. Stanford, Middlesex Hospital Medical School, London; Professor Freerksen, Borstel, Germany; the American Collection of Type Cultures; the Trudeau Institute; Professor A. L. Olitzki, Department of Bacteriology, Hebrew University-Hadassah Medical School, Jerusalem, Israel; Professor R. Cluzel, Department of Bacteriology-Hygiene, Faculty of Medicine, Clermont Ferrand, France; R. Lewit, Shmuel Harofe Hospital, Israel.

The work was supported by a grant from Nessim David Gaon of Geneva.

\section{REFERENCES}

Brosbe, E. A., Sugihara, P. T., Smith, C. R., and Hyde, L. 1964. Experimental drug studies on Mycobacterium fortuitum. Antimicrob. Agents Chemother., 4, 733.

Bulmer, C., AND Sexton, R. 1971. Comparative techniques for reproducing infectious corneal ulcers in monkeys and rabbits. Bact. Proc., p. 71. 
Dillon, M. I., AND Postlethwart, R. W. 1971. Pre- and postoperative prophylactic use of cephaloridine. A study of 201 cases. Am. J. Surg., 122, 61.

Dufour, A. P., Knight, R. A., AND Harris, H. W. 1966. Mycobacterial penicillinase activity. Am. Rev. Resp. Dis., 94, 965.

Gordon, Ruth E., AND SMITH, MilDRED M. 1955. Rapidly growing, acid fast bacteria. II. Species description of Mycobacterium fortuitum Cruz. J. Bact., 69, 502.

Griffith, R. S., AND BLACK, H. R. 1971. Blood, urine and tissue concentrations of the cephalosporin antibiotics in normal subjects. Postgrad. Med.J., 47, Feb. Suppl., 32.

HAND, W. L., AND SANFORD, J. P. 1970. Mycobacterium fortuitum. A human pathogen. Ann. Intern. Med., 73, 971.

Hawkins, J. E., AND MCClean, V. R. 1966. Effect of penicillin G and D-cycloserine on mycobacteria in vitro and in vivo. Am. Rev. Resp. Dis., 94, 118.

Kasik, J. E., and Peacham, L. 1968. Properties of $\beta$-lactamases produced by three species of mycobacteria. Biochem. J., 107, 675.

MolaVI, A., AND WeINSTEIN, L. 1971a. In-vitro activity of erythromycin against atypical mycobacteria. J. Infect. Dis., 123, 216.

Molavi, A., AND WeINSTEIN, L. 1971b. In vitro susceptibility of atypical mycobacteria to rifampin. Appl. Microbiol., 22, 23.

NakaYama, Y., Nakayama, H., AND TAKeYA, K. 1970. Studies of the relationship between Mycobacterium fortuitum and Mycobacterium runyonii. Am. Rev. Resp. Dis., 101, 558.

Nicholson, D. P., AND Sevier, W. R. 1971. Mycobacterium fortuitum as a pathogen. A case report. Am. Rev. Resp. Dis., 104, 747.

Portaels, F., ANd Pattyn, S. R. 1970. Resistance to ethambutol as an aid to the identification of Mycobacterium friedmannii (abscessus) and M. borstelense. J. Med. Microbiol., 3, 674.

STANFORD, J. L., AND BeCK, A. 1969. Bacteriological and serological studies of fast growing mycobacteria identified as Mycobacterium friedmannii. J. Gen. Microbiol., 58, 99.

Tsukamura, M. 1970. Differentiation between Mycobacterium abscessus and Mycobacterium borstelense. Am. Rev. Resp. Dis., 101, 426.

VAICHULIS, E. M. K., AND VICHER, E. E. 1962. Synergistic activity of penicillin and isoniazid on Mycobacterium fortuitum in vitro. Dis. Chest, 41, 553. 